\title{
MODEL MOBILE COMPUTING \\ UNTUK MENINGKATKAN LAYANAN E-GOVERNMENT DI TINGKAT DESA
}

(Studi Kasus: Desa Sumbermulyo Kecamatan Jogoroto Kabupaten Jombang Propinsi Jawa Timur)

\author{
Moh. Anshori Aris Widya ${ }^{1}$, Dana Indra Sensuse ${ }^{2}$ \\ ${ }^{1}$ Magister Teknik Informatika Universitas AMIKOM Yogyakarta \\ ${ }^{2}$ Doctor Fakultas Ilmu Komputer Universitas Indonesia Jakarta \\ E-mail: ${ }^{1}$ chemick86@gmail.com, ${ }^{2}$ dana@cs.ui.ac.id
}

\begin{abstract}
Abstrak
Di era digital seperti masa sekarang seluruh layanan berbasis elektronik tanpa terkecuali layanan pemerintah yang disebut e-government. E-government telah merambah diberbagai instansi pemerintahan akan tetapi masih sedikit yang direalisasikan ditingkat desa. Banyak faktor yang mempengaruhinya. Salah satunya adalah layanan administrasi didesa yang masih bersifat konvensional. Pemohon layanan datang ke balai desa untuk mendapatkan layanan administrasi. Jika kepala desa tidak ada ditempat, maka pemohon akan datang kembali di lain waktu sehingga memberikan ketidakpastian kepada pemohon. Hal tersebut juga dirasa akan mengurangi efektifitas waktu dari sisi pemohon. Solusi tepat yang dapat diberikan adalah menerapkan layanan e-government berbasis mobile computing. Dengan konsep layanan tersebut, pemohon tidak perlu datang ke balai desa saat pengajuan layanan akan tetapi cukup menggunakan aplikasi berbasis mobile. Untuk merealisasikan hal tersebut, maka dirancanglah sebuah model mobile computing yang berbasis SOA (Service Oriented Architecture). SOA sesuai jika diterapkan, dikarenakan SOA dapat mendukung berbagai layanan e-government lainnya di masa mendatang. Hasil yang didapatkan dari penelitian berupa sebuah model layanan berbasis SOA dengan service-service yang didapatkan dari layanan administrasi didesa. Selain itu hasil model rancangan berbasis SOA tersebut dapat direalisasi menggunakan arsitektur REST Web Service pada server online.
\end{abstract}

Kata Kunci-mobile computing, SOA, service, e-government

\begin{abstract}
In the digital era entire service use the electronic not exeption government services or calls e-government. E-government has penetrated various government agencies, but there are still few in the village level. Many factors that influence it. A factor is the administration service still used conventional method. The citizen came to the village hall to get administrative services. If the headman isn't there, the citizen will come back at another time. It's given uncertainty status to the citizen. It's considered to reduce the effectiveness time from the citizen. The right solution is implement e-government services based on mobile computing. The concept of the service, the citizen doesn't need to come to the village hall but simply use the mobilebased applications. This mechanism is realized by designed a model of mobile computing based on SOA (Service Oriented Architecture). SOA appropriate when applied because SOA can support a variety of other e-government services in the future. The results of this research is a service model based on SOA with the services from administrative services in the village. In addition, the results of the design model of SOA can be realized using the REST web service architecture on the online server.
\end{abstract}

Keywords-mobile computing, SOA, service, e-government

ISSN Print $\quad: 1979-7141$ 


\section{Pendahuluan}

Instruksi Presiden Nomor 3 Tahun 2003 Tentang Kebijakan dan Strategi Nasional Pengembangan $e$-Government merupakan landasan hukum dan langkah awal dalam penerapan e-Government pada segala sektor layanan publik yang diberikan oleh lembaga-lembaga pemerintah diseluruh Indonesia. Hal ini merupakan langkah strategis yang dapat merubah paradigma layanan publik menjadi lebih fleksibel dan lebih memprioritaskan pada kepuasan masyarakat. Seiring dengan implementasi e-Government pada lembaga-lembaga pemerintahan, berdampak semakin mudahnya transaparansi dan akuntabilitas pada akses terhadap informasi maupun layanan yang diberikan oleh lembaga-lembaga pemerintahan tersebut.

Salah satu faktor yang memungkinkan untuk implementasi e-Government tersebut dilapangan adalah karena perkembangan ICT (Information Communication Technology) semakin pesat dan meluas penggunaannya. Hal tersebut ditandai dengan semakin kompleksnya perangkat ICT yang dikembangkan oleh berbagai vendor. Salah satu perangkat yang cukup populer saat ini adalah perangkat mobile. Perangkat mobile hampir dimiliki oleh seluruh lapisan masyarakat dan dapat mengakomodir berbagai kebutuhan si pengguna mulai dari panggilan telepon, SMS (Short Message Service), browsing dan berbagai layanan yang memerlukan paket data. Implementasi e-Government saat ini masih terbatas pada pemerintahan di tingkat kecamatan dan belum menyeluruh mencapai pemerintahan di tingkat desa. Pada sebagian desa memang telah menerapkan beberapa sistem informasi yang secara khusus digunakan untuk menangani administrasi desa, akan tetapi alur layanan administrasi yang dilakukan tetap bersifat konvensional.

Alur layanannya yaitu pemohon datang secara langsung ke balai desa setempat untuk melakukan request akan layanan administrasi desa. Kekurangan dari proses ini adalah jika pejabat pengesahan Surat (kepala desa) tidak berada ditempat maka pemohon akan kembali ke balai desa lain waktu. Hal ini sangat menyita waktu disisi pemohon dan juga permohonan layanan hanya berlaku pada jam kerja saja. Hal tersebut mencerminkan bahwa layanan yang diberikan belum sepenuhnya efektif dan berkualitas. Sebuah konsep yang dapat dirancang untuk dapat memberikan solusi pada permasalahan tersebut adalah layanan Mobile Government berbasis SOA (Software Oriented Architecture). Alasan pemilihan teknologi mobile dan SOA dalam solusi dalam permasalahan ini dikarenakan teknologi mobile memiliki flexibitas yang tinggi dan SOA memiliki kemudahan dalam proses integrasi dan maintenance.

\subsection{Batasan Variabel Penelitian}

Batasan-batasan dalam penelitian ini antara lain:

1. Penelitian ini hanya membahas model mobile computing pada layanan administrasi kependudukan di desa.

2. Permasalahan yang dibahas dalam penelitian ini adalah permasalahan seputar layanan administrasi berupa pengajuan Surat oleh penduduk.

3. Layanan administrasi kependudukan yang dibahas dalam penelitian ini meliputi: Pengajuan Kartu Keluarga (KK), Pengajuan Kartu Tanda Penduduk (KTP), Surat Keterangan Catatan Kepolisian (SKCK), Surat Keterangan Domisili, Surat Keterangan Usaha, Surat Keterangan Kelahiran, Surat Keterangan Kematian, Surat Keterangan Kehilangan, Surat Keterangan Miskin dan Surat Model N.

4. Penelitian ini menggunakan metode SOA (Service Oriented Architecture)

5. Penelitian ini dilakukan di desa Sumbermulyo kecamatan Jogoroto kabupaten Jombang propinsi Jawa Timur

1.2 Tujuan Penelitian

Tujuan dilakukannya penelitian ini adalah untuk dapat merancang model mobile computing yang sesuai untuk layanan administrasi kependudukan di tingkat desa. 


\subsection{Ulasan Penelitian Sebelumnya}

Beberapa penelitian yang memiliki relevansi terhadap penelitian ini antara lain:

1. Arifin, S. Yusapril, E. [1] yang menjelaskan mengenai bagaimana usulan model $e$ Government dibuat pada pemerintahan di tingkat kelurahan dengan future portofolio yang dipetakan ke dalam McFarlan Analyst Grid. Pada penelitian mereka mengusulkan model e-Government yang ditempatkan pada kelurahan. Sedangkan pada penelitian ini, diusulkan model mobile government untuk layanan administrasi di tingkat desa.

2 Assar K. [2] yang membahas mengenai peranan Information Communication Technology (ICT) dan Implementasi M-Government pada layanan di sektor publik. Pada penelitian tersebut menghasilkan sebuah analisis terhadap main success factor dalam layanan publik. Sedangkan pada penelitian ini menghasilkan model mobile government.

3 Handayaningsih, S. Nugroho, H. [3] yang membahas pembangunan model sistem $\mathrm{m}$ Government yang digunakan untuk pelayanan publik yang bersifat rutin pada masingmasing instansi sehingga dapat mendukung strategi organisasi di pemerintah Kota Yogyakarta. Pada penelitian tersebut menghasilkan model $m$-Government secara luas pada berbagai instansi. Sedangkan pada penelitian ini menghasilkan model $\mathrm{m}$ Government pada tingkat desa.

\section{Metode Penelitian}

\subsection{Metode Penelitian}

Penelitian ini menggunakan pendekatan metode SOA (Service Oriented Architecture) dan waterfall. SOA adalah suatu cara perancangan aplikasi dengan menggunakan komponenkomponen atau pelayanan yang sudah ada tanpa harus merubah sistem yang telah ada dan hanya memerlukan penambahan modul-modul yang digunakan untuk mengintegrasikan sistem atau dengan kata lain disusun dalam bentuk modul (modular) [4]. Sehingga dapat disimpulkan bahwa metode SOA menjadikan fungsi-fungsi aplikasi sebagai layanan (service), yang dipaket sebagai komponen yang dapat digunakan secara berulang serta bersifat independence [5].

Metode SOA digunakan untuk melakukan pemodelan terhadap berbagai layanan administrasi di desa sedangkan waterfall digunakan untuk mengembangkan sistem secara keseluruhan.

Tahapan SOA sesuai dengan gambar 1 sedangkan tahapan waterfall sesuai dengan gambar 2 .

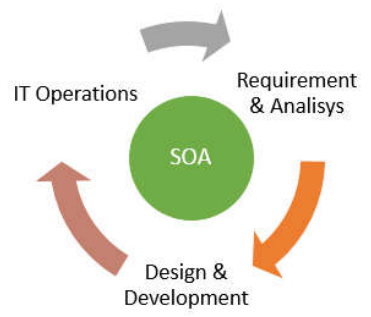

Gambar 2.1. Tahapan dalam SOA

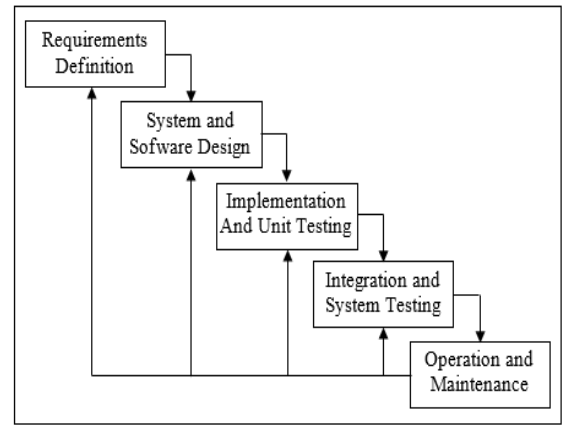

Gambar 2.2. Tahapan dalam Waterfall 


\subsection{Alur Penelitian}

Alur penelitian tersusun dari langkah-langkah yang tersistematis. Secara garis besar penelitian yang dilakukan sesuai dengan gambar 2.3.

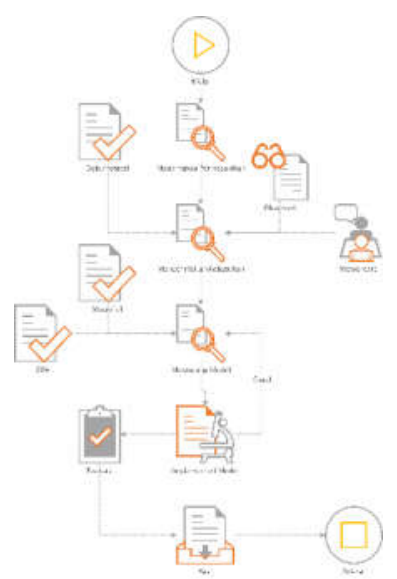

Gambar 2.3. Diagram Alur Penelitian

Pada tahapan awal penelitian, dilakukan tahapan menentukan permasalahan. Kemudian dilanjutkan dengan tahapan mendefinisikan kebutuhan. Pada tahapan mendefinisikan kebutuhan digunakan metode wawancara, observasi dan dokumentasi. Tahapan berikutnya adalah merancang model dengan metode SOA dan waterfall. Kemudian model tersebut diimplementasikan jika gagal maka akan kembali ke tahapan merancang model. Jika berhasil maka akan menuju tahapan evaluasi kemudian berakhir di tahapan hasil.

\section{Hasil dan Pembahasan}

3.1 Analisis dan Rancangan Sistem

Analisis kebutuhan didasarkan pada kemampuan apa saja yang dapat dilakukan oleh aplikasi yang akan dibangun. Analisis kebutuhan dalam membangun sistem e-Government berbasis mobile computing ini antara lain:

1. Fitur Aplikasi merupakan fungsi-fungsi layanan yang dapat dilakukan melalui aplikasi mobile government. Fitur-fitur aplikasi didapat dari dokumentasi dan wawancara dengan perangkat desa yang dilakukan pada tahapan pendefinisian kebutuhan.

Tabel 3.1. Fitur Layanan dalam Mobile Government

\begin{tabular}{|c|c|c|}
\hline No. & Fitur & $\begin{array}{c}\text { Penjelasan } \\
\end{array}$ \\
\hline 1 & $\begin{array}{l}\text { Layanan } \\
\text { Administrasi }\end{array}$ & $\begin{array}{l}\text { Layanan administrasi merupakan layanan dalam rangka } \\
\text { pengajuan surat yang dibutuhkan oleh warga. Beberapa } \\
\text { layanan surat yang terdapat layanan ini antara lain : } \\
\text { - Pengajuan Kartu Keluarga (KK) } \\
\text { - Pengajuan Kartu Tanda Penduduk (KTP) } \\
\text { - Surat Keterangan Catatan Kepolisian (SKCK) } \\
\text { - Surat Keterangan Domisili } \\
\text { - Surat Keterangan Usaha } \\
\text { - Surat Keterangan Kelahiran } \\
\text { - Surat Keterangan Kematian } \\
\text { - Surat Keterangan Kehilangan } \\
\text { - Surat Keterangan Miskin } \\
\text { - Surat Model N }\end{array}$ \\
\hline
\end{tabular}




\begin{tabular}{|c|l|l|}
\hline 2 & $\begin{array}{l}\text { Layanan History } \\
\text { Pengajuan Surat }\end{array}$ & $\begin{array}{l}\text { Merupakan layanan dimana warga dapat mengetahui } \\
\text { history pengajuan surat yang pernah dilakukan beserta } \\
\text { statusnya. }\end{array}$ \\
\hline 3 & $\begin{array}{l}\text { Layanan Informasi } \\
\text { Desa }\end{array}$ & $\begin{array}{l}\text { Merupakan layanan informasi desa yang meliputi } \\
\text { informasi kebijakan desa, informasi kegiatan, informasi } \\
\text { pendataan dan lain sebagainya. }\end{array}$ \\
\hline 4 & $\begin{array}{l}\text { Layanan Pelaporan } \\
\text { Kejadian }\end{array}$ & $\begin{array}{l}\text { Merupakan layanan dimana warga dapat melaporkan suatu } \\
\text { kejadian yang ada di daerah sekitar untuk diinformasikan } \\
\text { ke masyarakat lainnya. }\end{array}$ \\
\hline 5 & Layanan Notifikasi & $\begin{array}{l}\text { Merupakan layanan dimana aplikasi mobile government } \\
\text { memberikan pemberitahuan akan status pengajuan surat } \\
\text { yang dilakukan oleh warga }\end{array}$ \\
\hline
\end{tabular}

2. Kebutuhan Data merupakan data yang digunakan untuk merealisasikan fitur-fitur layanan pada aplikasi mobile government. Kebutuhan data terdiri dari berbagai macam data yang dimiliki oleh pemerintah desa Sumbermulyo.

Tabel 3.2. Tabel Kebutuhan Data

\begin{tabular}{|c|l|l|}
\hline No. & \multicolumn{1}{|c|}{ Jenis Data } & \multicolumn{1}{c|}{ Penjelasan } \\
\hline 1 & Data Penduduk & $\begin{array}{l}\text { Digunakan oleh aplikasi mobile government } \text { sebagai } \\
\text { identifier pengguna layanan administrasi. }\end{array}$ \\
\hline 2 & $\begin{array}{l}\text { Digunakan oleh aplikasi mobile government sebagai opsi } \\
\text { yang diberikan kepada pengguna untuk dilakukan } \\
\text { Administrasi } \\
\text { pemilihan akan layanan pengajuan surat yang dinginkan } \\
\text { oleh pengguna dan apa yang harus dipenuhi oleh } \\
\text { pengguna dalam request layanan tersebut. }\end{array}$ \\
\hline 3 & $\begin{array}{l}\text { Data Transaksi } \\
\text { Layanan } \\
\text { Administrasi }\end{array}$ & $\begin{array}{l}\text { Digunakan oleh aplikasi mobile government sebagai data } \\
\text { history pengajuan surat oleh warga sekaligus } \\
\text { pemberitahuan (notifikasi) akan status pengajuan surat } \\
\text { yang di request oleh pengguna }\end{array}$ \\
\hline
\end{tabular}

3. Mekanisme Layanan

Mekanisme layanan digunakan untuk mengidentifikasi alur layanan lama (konvensional) yang kemudian dirumuskan menjadi alur layanan baru melalui aplikasi mobile government.

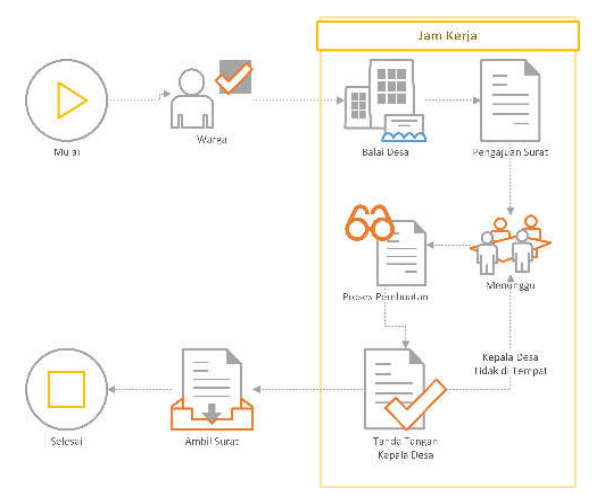

Gambar 3.1. Alur Mekanisme konvensional pada layanan administrasi 


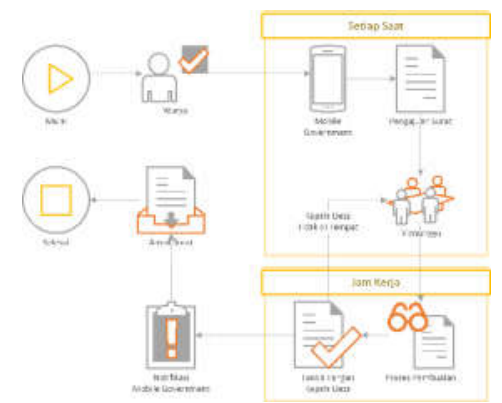

Gambar 3.2. Alur Mekanisme berbasis mobile pada layanan administrasi

Pemetaan service didasarkan pada proses bisnisnya, sehingga service-service tersebut ditempatkan pada beberapa layer service sesuai karakteristiknya masing-masing.

\begin{tabular}{|c|c|c|}
\hline $\begin{array}{l}\text { Orchestration } \\
\text { Service Layer }\end{array}$ & $\begin{array}{l}\text { Bussiness Service } \\
\text { Layer }\end{array}$ & $\begin{array}{l}\text { Application } \\
\text { Service Layer }\end{array}$ \\
\hline $\begin{array}{l}\text { - Service Layanan } \\
\text { Administrasi }\end{array}$ & $\begin{array}{l}\text { - Service } \\
\text { Pengelolaan } \\
\text { Data Penduduk } \\
\text { - Service Data } \\
\text { Surat } \\
\text { - Service Notif }\end{array}$ & $\begin{array}{l}\text { - Service KK } \\
\text { - Service KTP } \\
\text { - Service SKCK } \\
\text { - Service KD } \\
\text { - Service KU } \\
\text { - Service KL } \\
\text { - Service KM } \\
\text { - Service KH } \\
\text { - Service KS } \\
\text { - Service N }\end{array}$ \\
\hline
\end{tabular}

Gambar 3.3. Pemetaan Service Layanan Administrasi pada Layer Service

Model SOA yang dibangun mengacu pada penggunaan service bus dan web service. Service bus berperan sebagai penyedia jalur bagi aplikasi yang akan mengakses layanan. Sedangkan web service berperan sebagai penyedia layanan yang nantinya terhubung dengan database. Service bus merupakan layer terluar dan merupakan key enabler yang menangani protocol jaringan untuk menangani request dari service consumer. Layer orchestration berperan sebagai pengatur berbagai layanan yang ada di dalam layer web service. Web service merupakan inti dari layanan berbasis service ini. Layer ini berisi seluruh layanan yang ada baik dari business service mauapun application service. Business service secara otomatis berjalan di sistem sedangkan application service merupakan service yang berhubungan langsung dengan pengguna. Database layer merupakan pusat data yang dapat diakses melalui service-service dengan rule tertentu.

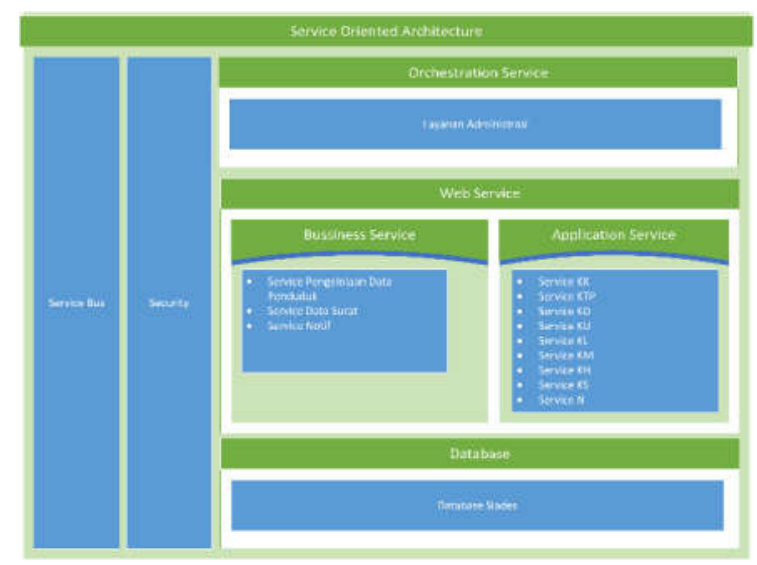

Gambar 3.4. Arsitektur Model SOA 
Model SOA pada layanan administrasi di desa Sumbermulyo ini terdiri dari 3 komponen utama yaitu Web Service, Aplikasi dan jaringan. Web Service merupakan bentuk implementasi dari SOA. Salah satu jenis Web Service yang sesuai untuk mendukung teknologi mobile adalah REST. REST (Representational State Transfer) merupakan sebuah aplikasi perangkat lunak yang mengacu pada model arsitektur untuk implementasi web service dalam bentuk web standar [7]. REST Web Service menangani request layanan yang berasal dari aplikasi mobile government sebagai service consumer. Request tersebut akan diproses dan dihubungkan dengan database jika rule business-nya memungkinkan.

Aplikasi mobile government berperan sebagai service consumer. Aplikasi mobile government mengirimkan request ke REST Web Service untuk diproses dan mengembalikan data jika diperlukan. Protocol jaringan digunakan untuk menghubungkan antara aplikasi mobile government dengan REST Web Service. Protocol jaringan yang digunakan dibagi menjadi 2 yaitu HTTP Request dan HTTP Response. HTTP Request digunakan untuk mengirimkan request layanan menggunakan method get, post atau yang lainnya dari aplikasi mobile government. Sedangkan HTTP Respone digunakan untuk mengirimkan data yang diinginkan dari REST Web Service ke aplikasi mobile government.

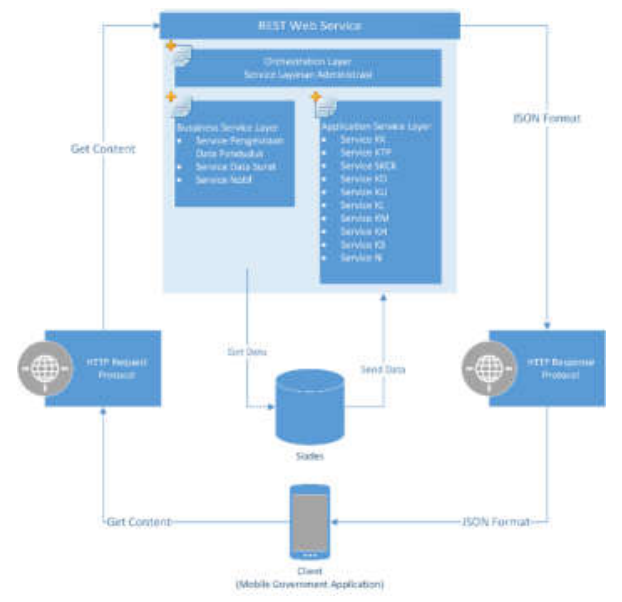

Gambar 3.5. Arsitektur Mobile Government

Perancangan database dilakukan untuk mengakomodir data yang dihasilkan dari sistem mobile government. Database yang dirancang tidak benar-benar baru, melainkan dilakukan penambahan pada database siades yang telah ada di desa. Desain penambahan pada database tersebut sesuai gambar 9 .

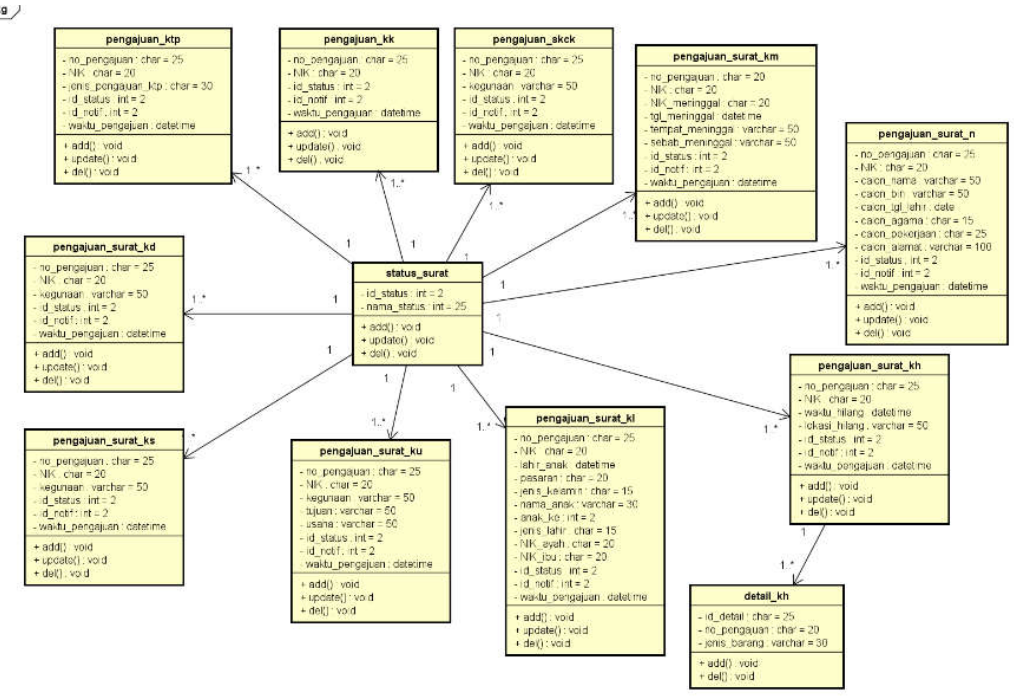

Gambar 3.6. Desain Database Mobile Government

ISSN Print $\quad: 1979-7141$ 


\subsection{Evaluasi}

Evaluasi sistem dilakukan dengan menggunakan metode blackbox testing. Pengujian blackbox didasarkan pada pengujian fungsionalitas sistem dengan suatu skenario tertentu.

Tabel 3.3. Skenario Pengujian 1

\begin{tabular}{|c|c|}
\hline \multicolumn{2}{|r|}{ Skenario 1} \\
\hline $\begin{array}{l}\text { Skenarion } \\
\text { Pengujian }\end{array}$ & Menguji Get Data Penduduk melalui service pengolahan data penduduk \\
\hline Tes Case & $\begin{array}{l}\text { http://152318211799.ip- } \\
\text { dynamic.com/webserv/ServPenduduk.php?nik=3517192007810005 }\end{array}$ \\
\hline $\begin{array}{l}\text { Hasil yang } \\
\text { diharapkan }\end{array}$ & $\begin{array}{l}\text { Sistem dapat menampilkan data penduduk berdasarkan NIK dalam format } \\
\text { JSON }\end{array}$ \\
\hline \multirow{4}{*}{ Hasil Pengujian } & 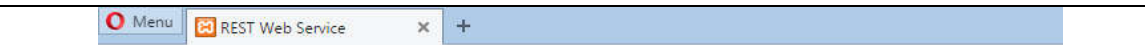 \\
\hline & 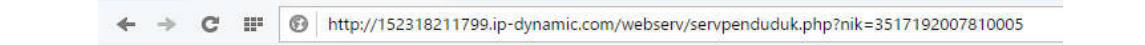 \\
\hline & 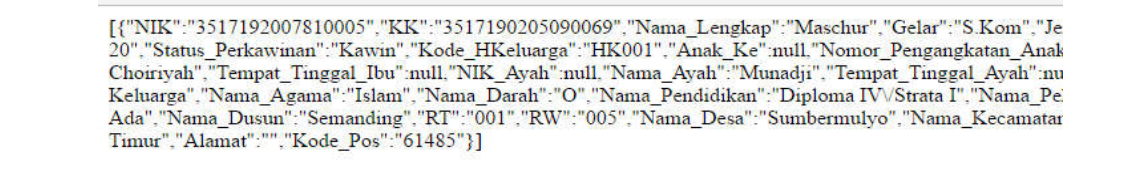 \\
\hline & Gambar 12. Screenshoot pengujian skenario 1 \\
\hline Ket & Berhasil \\
\hline Solusi & - \\
\hline
\end{tabular}

Tabel 3.4. Skenario Pengujian 2

\begin{tabular}{|c|c|}
\hline \multicolumn{2}{|r|}{ Skenario 2} \\
\hline $\begin{array}{l}\text { Skenarion } \\
\text { Penguiian }\end{array}$ & $\begin{array}{l}\text { Menguji Get Data Penduduk yang tidak aktif melalui service pengolahan } \\
\text { data penduduk }\end{array}$ \\
\hline Tes Case & $\begin{array}{l}\text { http://152318211799.ip- } \\
\text { dynamic.com/webserv/servpenduduk.php?nik=3516165705000004 }\end{array}$ \\
\hline $\begin{array}{l}\text { Hasil yang } \\
\text { diharapkan }\end{array}$ & $\begin{array}{l}\text { Sistem tidak dapat menampilkan data penduduk dikarenakan status } \\
\text { kependudukan yang tidak aktif }\end{array}$ \\
\hline \multirow{4}{*}{ Hasil Pengujian } & O Menu 䧃 REST Web Serice $\times+$ \\
\hline & 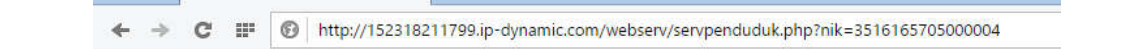 \\
\hline & 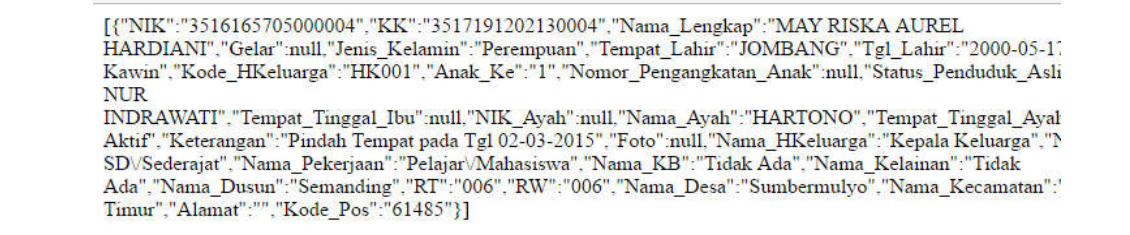 \\
\hline & Gambar 4.16 Screenshoot pengujian skenario 2 \\
\hline Ket & Seharusnya tidak muncul dikarenakan NIK tersebut tidak aktif. \\
\hline Solusi & Perbaikan pada Query \\
\hline
\end{tabular}

\section{Penutup}

\subsection{Kesimpulan}

Berdasarkan hasil penelitian model mobile computing dalam layanan e-government berbasis SOA, dapat disimpulkan sebagai berikut:

1. Fitur layanan mencakup layanan pengajuan KTP, pengajuan KK, pengajuan Surat Keterangan Catatan Kepolisian (SKCK), Surat Keterangan Domisili, Surat Keterangan Usaha, Surat Keterangan Kelahiran, Surat Keterangan Kematian, Surat Keterangan Kehilangan, Surat Keterangan Miskin dan Surat Model N. 
2. Arsitektur SOA (Service Oriented Architecture) yang dirancang direalisasikan menggunakan teknologi REST Web Service. REST Web service ditempatkan pada server milik desa Sumbermulyo dan terhubung dengan jaringan secara online.

3. Tool yang digunakan oleh warga dalam rangka request layanan administrasi kependudukan adalah aplikasi mobile government. Aplikasi mobile government ditempatkan pada perangkat mobile milik masing-masing warga dan terhubung secara online dengan service provider milik desa Sumbermulyo

\subsection{Saran}

Saran yang dapat diusulkan dari penelitian ini antara lain:

1. Implementasi server pada jaringan online harus menggunakan IP publik yang statik agar tidak terjadi perubahan pada lokasi server dalam jaringan online. Kendala yang muncul adalah jaringan pada desa Sumbermulyo menggunakan IP publik yang dinamis sehingga berubah-ubah saat modem restart. Solusi yang dapat dilakukan adalah menggunakan layanan pihak ke 3 seperti ip-dynamic.com yang dapat merubah mekanisme pengenalan lokasi pada jaringan online.

2. Saat melakukan integrasi pada database milik desa Sumbermulyo, harus dilakukan penelitian tentang database tersebut terlebih dahulu sehingga membutuhkan waktu penelitian lebih banyak lagi.

3. Model yang dirancang hanya dapat digunakan oleh warga yang memiliki perangkat mobile atau memiliki perangkat mobile yang dapat mendukung aplikasi mobile government.

4. Cakupan layanan administrasi dapat diperluas bagi penelitian berikutnya.

5. Model layanan dapat dikembangkan dengan teknologi USSD (Unstructured Supplementary Service Data) bagi penelitian berikutnya.

\section{DAFTAR PUSTAKA}

Arifin, S. Yusapril, E. 2016, "Model e-Government pada Wilayah Administrasi Pemerintahan Tingkat Kelurahan", Jurnal Politeknik Caltex Riau, Volume 2, No. 1.

Assar, K. 2015, "m-Government in Saudi Arabia”, International Journal of Advanced Research in Computer Science \& Software Engineering, Volume 5, Issue 1, ISSN: 2277-128x.

Handayaningsih, S. Nugroho, H. 2013, "Model Sistem M-Government (Studi Kasus: Pemerintah Kota Yogyakarta)", Jurnal Informatika, Volume 7, No. 22.

Slameto, A. 2015, "Integrasi Sistem Informasi Laboratorium dengan Menggunakan Pendekatan Service Oriented Architecture (SOA)", Jurnal Ilmiah Data Manajemen dan Teknologi Informasi (DASI), Volume 16, No. 3, ISSN: 1411-3201.

Shofa, R. Kurnia, B. 2013, "Penerapan Service Oriented Architecture (SOA) Dalam Pembangunan Web Based Learning", Jurnal Penelitian SITROTIKA, Volume 9, ISSN: 1693-9670.

Hutahean, J. Purba, E. 2016, "Rancangan Bangun E-Ticket Bioskop dengan Metode Waterfall Berbasis Web”, Riau Journal of Computer Science, Volume 2, No. 12, ISSN: 2477-6890.

Deitel, P. Deitel, H. 2011, "Visual C\# 2012 How to Program Fifth Edition", Pearson Education Limited, London. 